\title{
Mechanisms of long-term decline in size of lesser sandeels in the North Sea explored using a growth and phenology model
}

\author{
Morten Frederiksen ${ }^{1,2,3, *}$, David A. Elston ${ }^{4}$, Martin Edwards ${ }^{3}$, Alec D. Mann ${ }^{5}$, \\ Sarah Wanless ${ }^{1}$ \\ ${ }^{1}$ Centre for Ecology \& Hydrology, Bush Estate, Penicuik EH26 0QB, UK \\ ${ }^{2}$ Department of Arctic Environment, National Environmental Research Institute, Aarhus University, Frederiksborgvej 399, \\ 4000 Roskilde, Denmark \\ ${ }^{3}$ Sir Alister Hardy Foundation for Ocean Science, The Laboratory, Citadel Hill, Plymouth PL1 2PB, UK \\ ${ }^{4}$ Biomathematics and Statistics Scotland, Craigiebuckler, Aberdeen AB15 8QH, UK \\ ${ }^{5}$ Biomathematics and Statistics Scotland, The King's Buildings, Edinburgh EH9 3JZ, UK
}

\begin{abstract}
The lesser sandeel Ammodytes marinus is a key species in the North Sea ecosystem, transferring energy from planktonic producers to top predators. Previous studies have shown a longterm decline in the size of 0-group sandeels in the western North Sea, but they were unable to pinpoint the mechanism (later hatching, slower growth or changes in size-dependent mortality) or cause. To investigate the first 2 possibilities we combined 2 independent time series of sandeel size, namely data from chick-feeding Atlantic puffins Fratercula arctica and from the Continuous Plankton Recorder (CPR), in a novel statistical model implemented using Markov Chain Monte Carlo (MCMC). The model estimated annual mean length on 1 July, as well as hatching date and growth rate for sandeels from 1973 to 2006. Mean length-at-date declined by $22 \%$ over this period, corresponding to a $60 \%$ decrease in energy content, with a sharper decline since 2002. Up to the mid-1990s, the decline was associated with a trend towards later hatching. Subsequently, hatching became earlier again, and the continued trend towards smaller size appears to have been driven by lower growth rates, particularly in the most recent years, although we could not rule out changes in size-dependent mortality. Our findings point to major changes in key aspects of sandeel life history, which we consider are most likely due to direct and indirect temperature-related changes over a range of biotic factors, including the seasonal distribution of copepods and intra- and inter-specific competition with planktivorous fish. The results have implications both for the many predators of sandeels and for age and size of maturation in this aggregation of North Sea sandeels.
\end{abstract}

KEY WORDS: Ammodytes marinus $\cdot$ Growth model $\cdot$ MCMC $\cdot$ North Sea $\cdot$ Phenology $\cdot$ Sandeel

\section{INTRODUCTION}

Since the 1980s, profound changes in the structure and function of pelagic marine ecosystems have been observed in many parts of the world (e.g. Hunt et al. 2002, Beaugrand 2004), and these changes have often been linked to climatic warming. Planktonic organisms are generally very sensitive to temperature variation
(Hays et al. 2005), and increasing temperature has been implicated as the main driver behind changes in their distribution (Richardson \& Schoeman 2004), community composition (Beaugrand et al. 2002, Kirby et al. 2008) and phenology (Edwards \& Richardson 2004). Bottom-up processes in pelagic ecosystems are driven by planktonic primary and secondary production. The observed changes are thus expected to affect food web 
dynamics and to impact higher trophic levels, and indeed have already been linked with fluctuations in both commercially exploited fish stocks (Beaugrand \& Reid 2003, Beaugrand et al. 2003, Castonguay et al. 2008) and reproductive performance of land-based predators (Frederiksen et al. 2006, Sydeman et al. 2006).

The lesser sandeel Ammodytes marinus (hereinafter sandeel) is a key species in the ecology of the North Sea and other parts of the NE Atlantic (Daan et al. 1990). It is generally the most abundant small planktivorous fish, and provides a critical trophic link between secondary producers (zooplankton, particularly calanoid copepods) and a wide variety of top predators, including larger fish, marine mammals and seabirds. Several studies have highlighted the critical importance of the availability and quality of sandeels for successful reproduction of North Sea seabirds (Monaghan 1992, Rindorf et al. 2000, Wanless et al. 2005, Daunt et al. 2008). Sandeels are also the target of a major industrial fishery for fishmeal and fish oil (Furness 2002). However, evidence from several sources has indicated that conditions for sandeels in the North Sea are less favourable than they were in the past. For example, recruitment to the spawning stock has been very low since 2002, possibly linked to winter warming (Arnott \& Ruxton 2002, van Deurs et al. 2009). Total biomass and fishery landings have declined by over $50 \%$ (ICES 2007), and at least in some years lipid content of fish has been much lower than normal (Wanless et al. 2005). Long-term studies of sandeels obtained from breeding Atlantic puffins Fratercula arctica (hereinafter puffins) on the Isle of May in the western North Sea have also shown a gradual decrease in mean body length of first-year (0-group) fish from the 1970s to the 2000s, equivalent to a $40 \%$ decline in total energy content per fish (Wanless et al. 2004). A similar decrease was also observed in the mean length of larval sandeels captured by the Continuous Plankton Recorder (CPR) survey in the same area (Frederiksen et al. 2006). However, it was not clear whether this decline was due to later hatching, changes in size-dependent mortality or slower growth, and the underlying cause or causes were also unknown. The North Sea has experienced dramatic environmental changes since the 1970s, with increasing temperatures (Edwards et al. 2006), profound changes in plankton communities (Edwards et al. 2002), and shifting fish distributions (Perry et al. 2005, Dulvy et al. 2008). In particular, a major regime shift in the late 1980s linked to a sudden increase in winter temperatures had farreaching implications (Beaugrand 2004). However, the consequences of these changes for sandeels and their dependent predators are far from clear, largely due to a lack of fishery-independent long-term data on sandeel populations.
Here, we use data on sandeels caught by puffins and CPR survey samples from 1973 to 2006 to construct year-specific growth curves and describe long-term trends in hatching dates and growth rates. Our main aim is to evaluate to what extent the observed decrease in sandeel length might be associated with later hatching or slower growth. We discuss our findings in the context of the third plausible alternative (size-dependent mortality); we also consider some potential environmental drivers of temporal variation in sandeel life history parameters and their implications for some avian predators of sandeels.

\section{MATERIALS AND METHODS}

Data. Sandeel larvae were extracted from archived CPR samples collected between January and July from 1973 to 2006 within an area approximately centred on the seabird colony on the Isle of May $\left(56^{\circ} 11^{\prime} \mathrm{N}\right.$, $2^{\circ} 33^{\prime} \mathrm{W}$ ) and the Wee Bankie/Marr Bank sandeel aggregation (Pedersen et al. 1999, Boulcott et al. 2007), and extending from 54 to $59^{\circ} \mathrm{N}$, and from $2^{\circ} \mathrm{W}$ to $2^{\circ} \mathrm{E}$. 0 -group sandeels were collected from chick-feeding puffins on the Isle of May between late May and July each year from 1973 to 2006. All sandeels were measured to the nearest $\mathrm{mm}$, and have been treated as lying within $\pm 0.5 \mathrm{~mm}$ of the recorded length. (For full details on CPR data see Frederiksen et al. 2006; for samples from puffins see Wanless et al. 2004.) Although date of capture was always recorded, no corresponding estimates of age were made for individual fish. Annual sample sizes for both data sets are shown in Table 1. CPR data consisted mainly of larvae under $15 \mathrm{~mm}$ in length, whereas samples from puffins were mainly metamorphosed sandeels more than $40 \mathrm{~mm}$ in length. Thus there was little overlap in time (within season) or body length (among fish) in the 2 data sets. Moreover, the data were potentially subject to opposing selection biases, with larger larvae more likely to escape capture by the CPR and the very smallest sandeels not being brought in for puffin chicks. These probable selection biases make it problematic to fit growth curves and estimate hatching dates based on either of these data sources alone (Fig. 1). Here, we combine the 2 data sources into one statistical model, which allows greatly improved estimation of yearspecific growth parameters and hatching dates.

Growth model. The basic model for length of sandeels $\left(L_{T}\right)$ at time $T$ (Julian date, within year) is:

$$
L_{T}=L_{\infty}\left\{1-\exp \left[-K\left(T-T_{0}\right)\right]\right\}
$$

where $T_{0}(<T)$ is the date at which the growth curve has length zero, $L_{\infty}$ can be considered the maximum mean length in population studies or the maximum 
Table 1. Ammodytes marinus. Sample sizes of sandeel larvae and juveniles obtained from the Continuous Plankton Recorder (CPR) and chick-feeding puffins. Also shown are the numbers of individuals retained for analysis (see text for details)

\begin{tabular}{|c|c|c|c|c|}
\hline \multirow[t]{2}{*}{ Year } & \multicolumn{2}{|c|}{$\mathrm{CPR}-$} & \multicolumn{2}{|c|}{$\longrightarrow$ Puffin } \\
\hline & Total & Retained & Total & Retained \\
\hline 1973 & 73 & 73 & 321 & 195 \\
\hline 1974 & 45 & 45 & 387 & 198 \\
\hline 1975 & 8 & 8 & 79 & 79 \\
\hline 1976 & 11 & 11 & 395 & 200 \\
\hline 1977 & 51 & 51 & 276 & 203 \\
\hline 1978 & 60 & 60 & 256 & 206 \\
\hline 1979 & 8 & 8 & 212 & 203 \\
\hline 1980 & 7 & 7 & 0 & 0 \\
\hline 1981 & 57 & 57 & 262 & 205 \\
\hline 1982 & 67 & 67 & 109 & 109 \\
\hline 1983 & 53 & 53 & 426 & 202 \\
\hline 1984 & 13 & 13 & 370 & 200 \\
\hline 1985 & 181 & 181 & 804 & 207 \\
\hline 1986 & 81 & 81 & 155 & 155 \\
\hline 1987 & 55 & 55 & 164 & 164 \\
\hline 1988 & 265 & 186 & 709 & 191 \\
\hline 1989 & 57 & 57 & 568 & 207 \\
\hline 1990 & 122 & 122 & 450 & 210 \\
\hline 1991 & 71 & 71 & 782 & 205 \\
\hline 1992 & 13 & 13 & 599 & 182 \\
\hline 1993 & 119 & 119 & 728 & 196 \\
\hline 1994 & 213 & 200 & 756 & 201 \\
\hline 1995 & 62 & 62 & 344 & 187 \\
\hline 1996 & 97 & 97 & 852 & 196 \\
\hline 1997 & 75 & 75 & 639 & 211 \\
\hline 1998 & 71 & 71 & 2871 & 174 \\
\hline 1999 & 235 & 199 & 1441 & 193 \\
\hline 2000 & 64 & 64 & 1732 & 202 \\
\hline 2001 & 95 & 95 & 1852 & 203 \\
\hline 2002 & 123 & 123 & 1592 & 177 \\
\hline 2003 & 133 & 133 & 2280 & 206 \\
\hline 2004 & 90 & 90 & 3425 & 225 \\
\hline 2005 & 82 & 82 & 2777 & 214 \\
\hline 2006 & 173 & 173 & 2055 & 204 \\
\hline
\end{tabular}

length if used for an individual, and the parameter $K$ $(>0)$ controls the proportional rate of growth towards $L_{\infty}$ such that each time increment of $\log (2) / K$ leads to a halving of the difference between $L_{T}$ and $L_{\infty}$. This 3parameter model with exponential approach to an asymptote (the von Bertalanffy growth model) is among the simplest available for non-linear growth. Although it has contrasting motivations, we have selected it as being empirically plausible. This model may be an oversimplification of the growth of individual sandeels, as metamorphosis from larva to young fish probably results in changes in allometry, thus disrupting the smooth growth pattern implied in the model. However, with only one length-at-date record per fish, the data set did not seem suitable for the additional complexities associated with fitting a 2phase growth model.

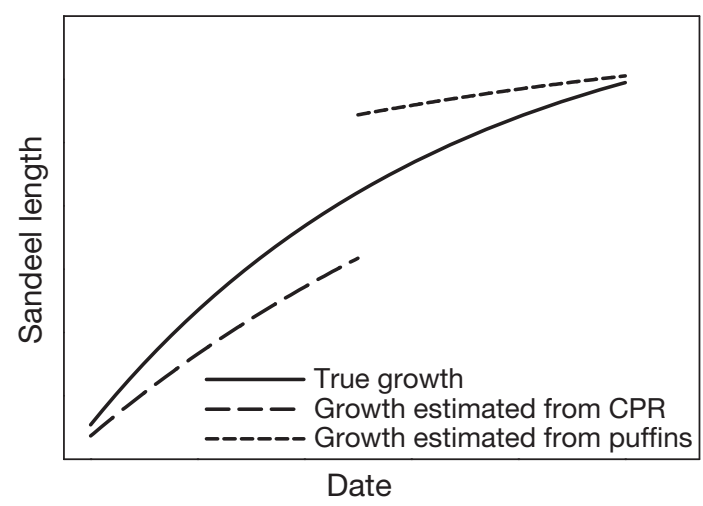

Fig. 1. Ammodytes marinus. Demonstration of how selection biases can lead to problems when estimating growth curve parameters. True growth is assumed to follow a von Bertalanffy pattern, i.e. an exponential approach to an asymptote. If the Continuous Plankton Recorder (CPR) preferentially catches small larvae, growth rate and asymptotic size will be underestimated, whereas estimation of hatching date should be unaffected. Conversely, if puffins actively avoid very small fish, estimates of growth rate and hatching date will be affected, whereas mean size should be unbiased once most fish are above the selection threshold. In order to overcome these estimation problems, we combine the 2 data sets and explicitly model selection bias in the CPR data

This basic model required further development to make it suitable for the sandeel data. (1) A specification of the model in which the parameters can be estimated stably had to be selected. (2) We needed to introduce annual variation for all parameters, since the objective was to describe long-term variation in growth, and to allow for individual-specific variation about the underlying year-specific growth curves. Rather than introducing 'measurement error' terms, we chose to do this by allowing for distributions of individual-specific parameter values around annual means, which themselves are distributed around global means. (3) We had to develop an observation model that allows for selectivity-induced biases in the 2 data sources: sandeels caught by the CPR and those caught by puffins. (4) We needed to allow for computational efficiency.

Stable estimation of parameters: Whilst in some years the mean size of sandeels changed little over the later part of the observation period, in other years the mean size changed approximately linearly. In the latter type of year, $L_{\infty}$ would be only poorly, hence unstably, estimated relative to the former type of year, and the distribution of year-specific estimates of $L_{\infty}$ would be strongly right-skewed. We therefore reformulated the model in terms of length $L_{R}$ at a reference date, $T_{R}$ taken to be Julian day 182.5 (i.e. between 1 July and 2 July in non-leap years, and between 30 June and 1 July in leap years - for simplicity referred to as 
1 July throughout). Calculating $L_{R}$ from Eq. (1) and substituting out $L_{\infty}$ gives:

$$
L_{T}=L_{R}\left\{1-\exp \left[-K\left(T-T_{0}\right)\right]\right\} /\left\{1-\exp \left[-K\left(T_{R}-T_{0}\right)\right]\right\}(1 \mathrm{a})
$$

Models for $L_{R}, T_{0}$ and $K$ : A principal objective was to look for changes in sandeel phenology, which could be achieved by modelling inter-annual variation in the values of $T_{0}$. For simplicity, the 3 year-specific parameters were considered to be independent of one another, an assumption that was tested by calculating the correlations between annual estimates. The spread of dates within years over which larvae of the smallest $(5 \mathrm{~mm})$ length class were collected suggested that $T_{0}$ also varied between individuals within years. Furthermore, individual-specific variation in $T_{0}$ was required because larvae caught early in the year varied substantially in size on any given date, implying again that hatching occurred over a period of several weeks. $L_{R}$ was expected to vary between years, and could also be seen to vary between individuals from the range of size-classes captured during years in which the mean length was stable after the reference time $T_{R}$. We assumed that the variances of individual-specific terms are constant across years. Sources of variation in $K$ were less evident from the raw data, and with only 1 observation per fish we did not consider that the data would support estimation of individual-specific values for $K$ as well. Consequently we took $K$ to be a function of year alone. To describe these models, we need the notation $y(i)$ to denote the year of capture of the $i$ th fish, simplified to $y$ when no specific fish is being referred to.

In line with the above, we decomposed the value of $T_{0}$ for fish $i, t_{0, i}$ into an overall mean $\left(\mu_{t}\right)$, a year-specific term of principal interest $\left(\delta_{t, y(i)}\right)$, and a fish-specific term $\left(e_{t, i}\right)$. All terms except the overall mean were treated as random effects from normal distributions, with SD to be estimated. The resulting equations then were:

$$
t_{0, i}=\mu_{t}+\delta_{t, y(i)}+e_{t, i}
$$

coupled with the random-effect distributional assumptions:

$$
\delta_{t, y} \sim N\left(0, \sigma_{\delta t, y}\right), e_{t, i} \sim N\left(0, \sigma_{e t}\right)
$$

where $z \sim N(a, b)$ indicates that the variable $z$ follows a normal distribution with mean $a$ and standard deviation $b$. The term $e_{t, i}$ never appears explicitly in our calculations, rather it appears implicitly via the equation $t_{0, i} \sim N\left(\mu_{t}+\delta_{t, Y(i)}, \sigma_{e t}\right)$ and contributes to the likelihood through the probability of fish-specific growth curves extrapolating back to zero within a particular range of dates.

In a similar vein, we decomposed the individualspecific values for $L_{R}$, denoted $l_{R, i}$ into 3 terms, which are analogous to those used for $t_{0, \mathrm{i} \text {. }}$ Thus:

$$
l_{R, i}=\mu_{1}+\delta_{l, Y(i)}+e_{l, i}
$$

coupled with 2 random-effect distributional assumptions:

$$
\delta_{l, y} \sim N\left(0, \sigma_{\delta l, y}\right), e_{l, i} \sim N\left(0, \sigma_{e l}\right)
$$

The third generic parameter, $K$, is considered to be year-specific only, the year-specific values, $k_{y \prime}$, being modelled on a log scale as:

$$
\log \left(k_{Y}\right)=\mu_{k}+\delta_{k, Y}
$$

both to enforce the positivity constraint on $k_{y}$ and to stretch the scale close to zero (which corresponds to nearly-linear growth curves). Since there was no direct evidence to suggest the shape parameter needed to be fish-specific, in the interests of parsimony we did not entertain this as a possibility and therefore have just a single associated random effect with distributional assumptions:

$$
\delta_{k, Y} \sim N\left(0, \sigma_{\delta k, Y}\right)
$$

Observation model: The observation model has potentially 3 elements.

The first element relates to the probability of fish $i$ on day $t_{i}$ of year $y(i)$ lying in the $j$ th length interval, with lower-bound $g_{j}$ and upper-bound $g_{j+1}$, given the yearand individual-specific parameters described above, conditional on the values of all model parameters. We allowed for 136 such intervals, each of width $1 \mathrm{~mm}$, with mid-points ranging from 1 to $136 \mathrm{~mm}$. Each conditional probability was calculated by inverting the growth model to obtain the equivalent length-zero dates associated with the upper and lower bounds. Care is required in such calculations to ensure that the logical constraint of monotonic growth is not violated. For example, if an observation took place before the reference day, so that $t_{i}<t_{r}$, then the observation is possible only if $g_{j}<1_{r, i}$. If $g_{j+1}>1_{r, i}$ then we must temporarily consider $g_{j+1}=l_{r, i}$ with numerical adjustment to avoid an infinity in the following calculations:

$$
\begin{gathered}
t_{j, i}=\left\{\log \left[\left(l_{t, i}-g_{j}\right) /\left(l_{t, i} \exp \left(-t_{r} k_{Y(i)}\right)-g_{j} \exp \left(-t_{j} k_{Y(i)}\right)\right)\right]\right\} / k_{Y(i)} \\
(5 a) \\
t_{j+1, i}=\left\{\log \left[\left(l_{t, i}-g_{j+1}\right) /\left(l_{t, i} \exp \left(-t_{r} k_{Y(i)}\right)-g_{j+1} \exp \left(-t_{j} k_{Y(i)}\right)\right)\right]\right\} / k_{Y(i)}
\end{gathered}
$$

The conditional probability of starting dates lying in the interval bounded by $t_{j, i}$ and $t_{j+1, i}$ can be obtained by integration of the normal density function with mean $t_{0, y(i)}$ and SD $\sigma_{e t}$ between these limits (from Eq. 2). This probability of occurrence is defined as $p_{j, i}$.

The second element relates to the probability that fish $i$ observed on day $t_{i}$ of year $y(i)$ has a length in the $j$ th length interval, with lower bound $g_{j}$ and upper bound $g_{j+1}$, conditional on the values of all model parameters. These probabilities of observation are not the same as the probabilities of occurrence, $p_{j, i}$ defined 
above, due to length-specific selectivities $q_{j}$, such that the relative probability of observing a fish in the $j$ th length interval is proportional to $p_{j, i} q_{j}$. Calculation of the probability of observing a fish in a particular length class is then a normalisation of the $p_{j, i} q_{j}$ over all length classes so that the sum of these values across length classes is 1 . Thus, if $j^{\prime}{ }_{i}$ is the observed length class for fish $i$, then this happens with probability $\pi_{i}=p_{j^{\prime}, i} q_{j^{\prime}}{ }^{\prime}$ $\sum_{j} p_{j, i} q_{j}$.

We assume a logistic selectivity function for the CPR data, parameterised as:

$$
\operatorname{logit}\left(q_{j}\right)=u+v\left[0.5\left(g_{j}+g_{j+1}\right)-h\right]
$$

Thus, the selectivity function is determined by the midpoint of the length interval, and is centred on $h=7 \mathrm{~mm}$, chosen arbitrarily for convenience. Initial attempts to model selectivity also allowed for selectivity for the puffin-caught sandeels, but this model was clearly overparameterised and selectivity for the puffincaught sandeels was therefore dropped. Comparisons of sizes of sandeels caught on the same day by puffins and in trawl nets indicated a 1:1 relationship and no evidence of puffins showing strong selection for larger fish (Wanless et al. 2004). Subsequent simplification led to setting $u=\log (0.9 /(1-0.9))$ (equivalent to probability of capture $=0.9$ for the length class centred on $7 \mathrm{~mm}$ ), leaving $v$ to be estimated.

The third element relates to the number of fish in the data set for each combination of day and method of capture. This could be informative if sufficient information were available concerning sampling effort. However, due to lack of such information we chose to ignore this element.

Specifying the likelihood: The likelihood of the data in the hierarchical model above is specified through the product over all fish of the values $\pi_{i}$ in combination with contributions from the random-effect distributions detailed above.

Inference: The model described above is non-linear, with many parameters and a likelihood that requires evaluation by numerical integration. Consequently, we chose to make inference by sampling from the likelihood using Markov Chain Monte Carlo (MCMC) methods. The MCMC was implemented in R, using Metropolis-Hastings steps with symmetric (normal) proposal distributions for simplicity. All parameters were updated on their natural scale except the SD of the random-effect distributions, which were updated on a log scale. Flat priors were used throughout on the scale of updating, and hence were omitted from the acceptance probabilities. However, whilst mathematically adequate, the above model specification was not convenient for inference by MCMC and we therefore made some computational improvements, described in the following section.
Computational improvements: In its full form, the sandeel data set was very large, containing lengths of 33598 fish. This was too large to handle conveniently: run-time increases linearly with number of fish, and the number of sandeels obtained from puffins in later years increased by an order of magnitude (Table 1). Thus for combinations of year and capture mechanism where sample size exceeded 200, fish were selected at random, with inclusion probabilities of 200/(sample size), giving expected sample sizes of 200 and realised sample sizes close to this value (Table 1 ). This reduction in information decreased run-time by a factor of 3 but still left a data set with 9112 fish (2802 from the CPR, 6310 originally caught by puffins).

The computationally most expensive part of evaluating the likelihood is calculating the $9112 \times 136=$ 1239232 distinct values of $p_{j, i}$ each requiring a normal integral. Hence specifying the model so that these calculations were performed as infrequently as possible was critical.

As laid out in Eq. (2a), changing either of $\mu_{t}$ or $\delta_{t}$ requires re-evaluation of $t_{0, i}$ and hence re-evaluation of all $p_{j, i}$. We chose instead to reformulate the model as:

$$
t_{0, i}=\delta_{t, y(i)}+e_{t, i} \delta_{t, Y} \sim N\left(\mu_{t,} \sigma_{\delta t, y}\right), e_{t, i} \sim N\left(0, \sigma_{e t}\right)
$$

thereby avoiding the need to re-evaluate all $p_{j, i}$ when updating $\mu_{t}$. Likewise in place of Eqs. (4a) \& (4b) we obtain:

$$
k_{y} \sim N\left(\mu_{k \prime} \sigma_{\delta k, y}\right)
$$

allowing fast updating of $\mu_{k}$, whilst Eqs. (3a) \& (3b) were replaced with the formulation:

$$
l_{r, i} \sim N\left(\delta_{l, Y(i)}, \sigma_{e l}\right), \delta_{l, y} \sim N\left(\mu_{l,} \sigma_{\delta l}\right)
$$

which allows for rapid updating of both $\mu_{l}$ and $\delta_{l, y}$.

The above model was implemented in bespoke $R$ code. The full set of parameters to consider updating in each iteration of the MCMC scheme was: $\left\{\mu_{t \prime} \delta_{t,} \mu_{k^{\prime}} \delta_{k t}\right.$ $\mu_{l \prime} \delta_{l \prime} \sigma_{\delta, t} \sigma_{\delta, k \prime}, \sigma_{\delta, l t} v_{C P R}, \sigma_{e t} e_{l}$ and $\left.\sigma_{e l}\right\}$, where $\delta_{t \prime} \delta_{k \prime}$ and $\delta_{l}$ are vectors of year-specific terms and $e_{l}$ is a vector of individual-specific terms. All proposal distributions were Gaussian, either on the scale of the parameters in question or, in the case of the SD of random effects, on a log-transformed scale. Block-updating was used for the year-specific vectors, hence either all or no proposed changes were accepted at each iteration. SD of the proposal distributions were tuned during program development to give acceptance rates of between 25 and $40 \%$, with the exception of $e_{l}$, for which the element-wise acceptance rates were considerably higher. Bayesian priors were flat on the scale at which updating was carried out. We set 4 independent chains running from early in program development and testing, of which one was dropped following implausible behaviour. The other 3 chains were maintained 
throughout development and, once finalised, were run for 420000 iterations, of which the first 100000 were discarded as burn-in. Convergence was assessed visually through trace-plots and analytically through the potential scale reduction factor (PSRF, Gelman \& Rubin 1992) for which an upper 0.975 quantile of $<1.2$ has been given as a rule of thumb to indicate convergence (Smith 2007). We also conducted analyses of variance on the year-specific medians to assess the extent to which variation between years was dominating variation between chains within years. Model fit was assessed visually, for each year, plotting both the observations and the expected mean values of observations with and without selectivity. The mean values were calculated by averaging over the distributions of individual-specific hatching dates and lengths at the reference date.

Presentation of simulation results: For illustration purposes, we present the following summaries of the simulated values for the year-specific growth curves: mean lengths $l_{r}$ (strictly, predicted mean length in $\mathrm{mm}$

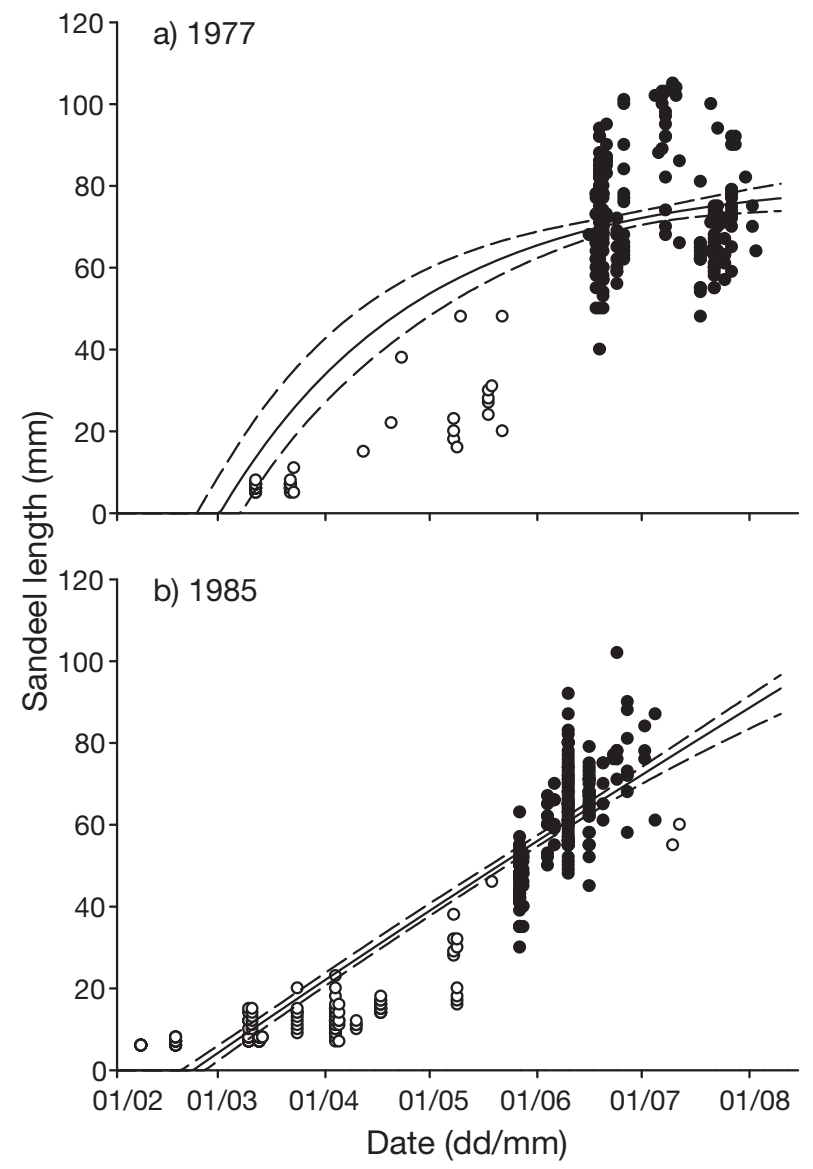

Fig. 2. Ammodytes marinus. Observed and modelled sandeel length for (a) 1977 and (b) 1985, 2 contrasting years. @: puffin data; O: CPR data. Also shown are the modelled growth curves using the median parameter values for each year, with $95 \%$ CI at the reference date, $1 \mathrm{July})_{;}$mean hatching date $t_{5}$ (predicted mean date when length $=5 \mathrm{~mm}$ ); and mean growth rate $b$ (slope in $\mathrm{mm} \mathrm{d}^{-1}$ of the line joining yearspecific growth curves at $t_{5}$ and $l_{r}$ ). Because $5 \mathrm{~mm}$ was the smallest recorded size of sandeel larvae, we assumed $t_{5}$ to be an estimate of mean hatch date. The 2 latter parameters were derived and thus did not appear in the likelihood, but they could be calculated from parameters stored during the model runs and hence treated in the same manner as mean length. For descriptive purposes, we estimated trends over time in growth parameters using ordinary linear regression of posterior means against calendar year, as well as piecewise regression (which can identify potential 'break points') and generalised additive modelling (GAM, using a spline smoother with the degree of smoothing determined through generalised crossvalidation).

\section{RESULTS}

Trace plots and diagnostic plots indicated satisfactory convergence for the majority of year-specific values for the summaries selected for presentation. Although some summaries did not pass the rule-ofthumb test for PSRF, this is a test for convergence of each summary in isolation. From the trace plots, it was clear that the variation between years was substantially greater than the variation between and within chains, an observation confirmed by analysis of variance, with $F_{33,66}$ statistics of $>800$ for each of mean length, mean hatch date and mean growth rate. SD for individual-specific parameters were (means $\pm \mathrm{SD}$ of the SDs [sd]) 12.7 (sd 0.1) $\mathrm{mm}$ for $L_{R}$ and 11.3 (sd 0.3) d for $T_{0}$ : the corresponding values for year-specific standard deviations were 8.3 (sd 1.1) $\mathrm{mm}$ and 11.1(sd 1.6) d. These figures indicate that variation between individuals exceeds variation between years for $L_{R}$, although, given the large numbers of puffin-caught fish, the year-specific mean values for $L_{R}$ are well estimated. For $T_{0}$, these 2 sources of variation are approximately in balance. The strongest correlation between annual parameter estimates was -0.16 between $L_{R}$ and $T_{0}$, suggesting that the simplifying assumption of independence was not unreasonable. Observations and fitted curves for data from puffins and CPR are given for 2 contrasting years in Fig. 2, one showing continued growth, the other showing a diminishing rate of growth. The trends presented below have been derived giving each year equal weight; similar results were achieved in alternative analyses involving inverse weighting by variance or deletion of years for which the summaries selected for presentation failed the rule-of-thumb test for PSRF. 
The mean length of 0-group sandeels on 1 July decreased markedly over the study period (Fig. 3a). This decline was highly significant (linear regression, $\mathrm{p}<0.0001, \mathrm{r}^{2}=40 \%$ ) and corresponded to a $22 \%$
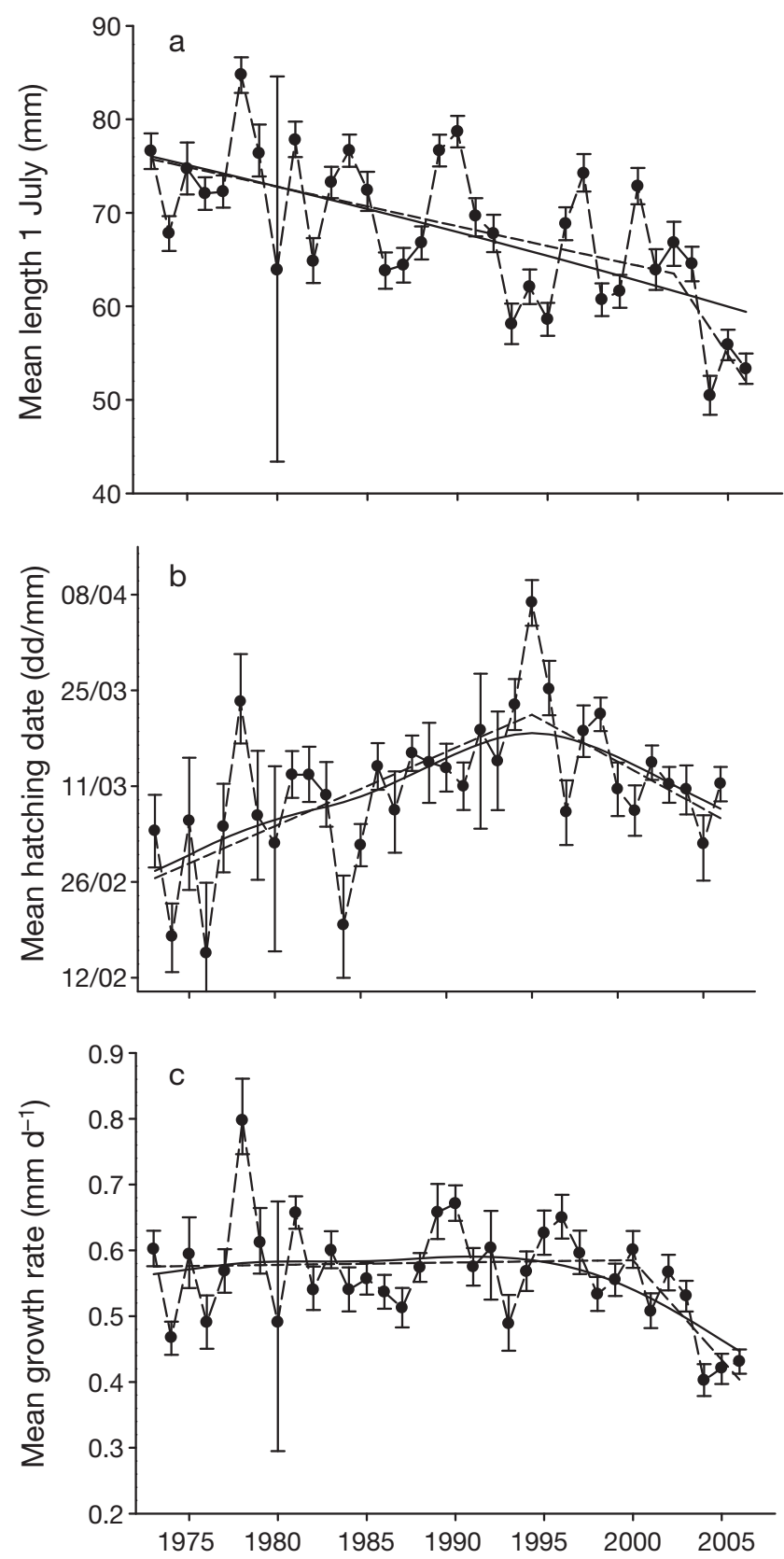

Fig. 3. Ammodytes marinus. Long-term changes in parameters of the sandeel growth model: (a) predicted length (mm) at the reference date, 1 July, (b) predicted hatch date (date when length $=5 \mathrm{~mm}$ ) and (c) linear approximation of growth rate between these 2 points $\left(\mathrm{mm} \mathrm{d}^{-1}\right)$. Shown are posterior means and $95 \%$ CI, along with predicted values from piecewise regression (dashed lines) and generalised additive modelling (solid lines) decline in length over the 34 yr period, although there was little change from 1995 to 2003. Piecewise regression identified a break point in 2002 (95\% CL: 1996-2008, $\mathrm{p}=0.024$, model $\mathrm{R}^{2}=48 \%$ ), whereas GAM did not identify any deviation from a linear trend (Fig. 3a). Fish were thus substantially smaller in the 3 most recent years (from 2004 to 2006) than previously observed.

Mean hatch date tended to become later up to 1995 (from 1973 to 1995, up to $1.1 \mathrm{~d} \mathrm{yr}^{-1}$ later), and then earlier (from 1996 to 2006, $1.2 \mathrm{~d} \mathrm{yr}^{-1}$ earlier, Fig. 3b). Over the entire study period, the linear trend towards later hatching was significant ( $\left.p=0.016, r^{2}=17 \%\right)$. Piecewise regression identified a highly significant break point in 1995 (95\% CL: 1990-2000, p = 0.0001, model $\mathrm{R}^{2}=42 \%$ ), and GAM showed a very similar pattern (Fig. 3b).

There was no clear trend over the study period in the linear approximation to growth rate, but in the period from 2004 to 2006 we observed substantially lower growth rates than we had previously seen (mean from 2004 to $200627 \%$ lower than mean from 1973 to 2003, Fig. 3c). No significant overall linear trend in growth rate was observed $\left(\mathrm{p}=0.063, \mathrm{r}^{2}=10 \%\right)$. However, piecewise regression identified a significant break point in 2000 (95\% CL: 1996-2004, p = 0.0005, model $\mathrm{R}^{2}=33 \%$ ), which was corroborated by GAM, indicating that growth rates were subsequently much lower than previously observed (Fig. 3c). There was a positive correlation $(r=0.46)$ between hatch date and growth rate, suggesting that, on average, growth was faster in years when hatch dates were later (Fig. 4). Again, growth-rate data points from 2004 to 2006 appeared to be outliers with unusually low growth rates relative to hatch date.

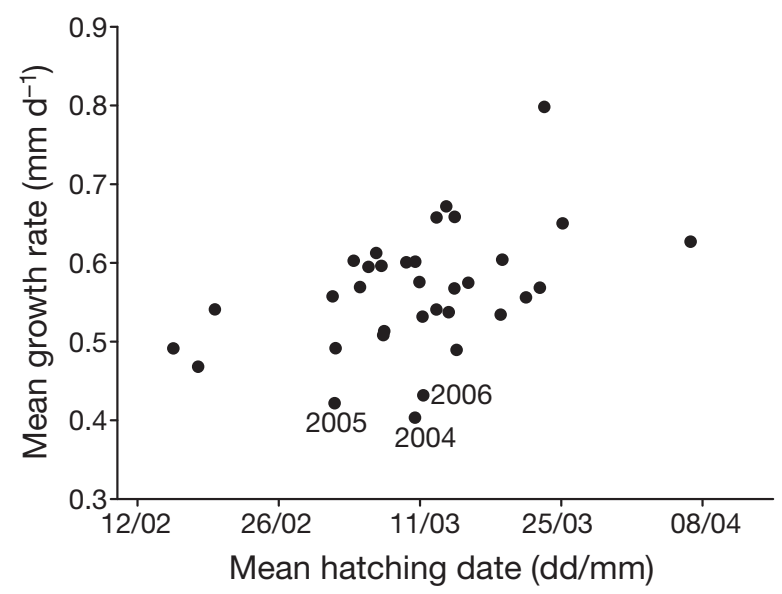

Fig. 4. Ammodytes marinus. Annual estimates of growth rate (see Fig. 3c) plotted against predicted hatch date (see Fig. 3b). The 3 years with exceptionally poor growth $(2004,2005$ and 2006) are labelled 


\section{DISCUSSION}

In this study we have developed a novel modelling framework to combine 2 high-quality long-term data sets on sandeel body lengths. This allowed us not only to provide support for a previously reported long-term decline in 0-group size in the Wee Bankie aggregation (Wanless et al. 2004), but also to describe temporal trends in 2 key aspects of sandeel biology, namely hatching dates and growth rates. Our approach was based on the plausible assumption of shared withinyear growth curves between fish originating from CPR and puffin samples, combined with a model for selectivity of a kind used regularly in fisheries research (e.g. Millar \& Fryer 1999). Fitting this model, with its yearand individual-specific parameters, and using MCMC methods, involves a substantial computational cost, and estimation of the selectivity model is hampered by the bulk of the lengths of CPR fish lying close to the hatching length $(5 \mathrm{~mm})$ class. Nevertheless, we consider that the approach represents a major advance over previous analyses, which have looked at the 2 time series in isolation (Wanless et al. 2004, Frederiksen et al. 2006). We discuss the results, first ignoring the confounding effects of changing patterns of predation on sandeels, and then considering the impact this confounding effect may have.

Results from the model suggested that the decline in 0-group sandeel body length showed a relatively consistent trend except for a discontinuity around 2002, with lengths declining more sharply after this (Fig. 3a). However, examination of the 2 proximate mechanisms potentially driving this change indicated a more complex situation. Thus, from the early 1970s to the mid-1990s, changes in 0-group length were associated primarily with a phenological change, with hatch dates becoming later by $\sim 1 \mathrm{~d} \mathrm{yr}^{-1}$ (Fig. 3b). The observed reduction in mean length at 1 July over this period was thus predominantly because fish were younger. However, from the mid-1990s to the end of the study, hatch dates became earlier again, also at a rate of $\sim 1 \mathrm{~d} \mathrm{yr}^{-1}$, and thus sandeel length at the standardised date would have been expected to increase. No such reversal was apparent; indeed from 2002 onwards mean lengths declined markedly, indicating that, despite being older, fish were smaller, and thus a reduction in growth rate was the principal driver (Fig. 3c). This alternation in importance of phenology and growth rates for 0-group length-atdate can be visualised by comparing results from the mid-1980s with the mid-2000s. In both periods hatch date was around Julian date 65 (Fig. 3b), but mean 0 -group length in the mid-1980s was around $72 \mathrm{~mm}$ compared to only about $55 \mathrm{~mm}$ by the mid-2000s (Fig. 3a).
In terms of the environmental conditions that might influence sandeel growth and phenology, changes in the abundance or timing of copepod production could be important-copepods being the main prey of sandeels in the North Sea (Macer 1966). Copepod biomass peaks later and for a shorter period in the Firth of Forth/Wee Bankie region than elsewhere in the North Sea (Fransz et al. 1991). It is possible that this effect will have become more marked following recent changes in the community composition and abundance of North Sea copepods associated with rising sea temperatures (Beaugrand et al. 2002, Edwards et al. 2002). Temperature changes are also likely to influence sandeel phenology and growth directly through physiological and behavioural responses, since all aspects of life history (including dates of emergence from the sand and spawning, egg development rate, larval growth and starvation mortality) are likely to be affected. Sea surface temperatures (SST) in the North Sea have increased considerably over the last 3 decades (Mackenzie \& Schiedek 2007, Kirby et al. 2009), and increasing temperature has recently been implicated as a driver of changes in phenology and growth of other fish spp in the region (Brunel \& Dickey-Collas 2010, Genner et al. 2010). While it is clear that summer SST on sandbanks off the Scottish east coast have increased (Hughes 2004), little is known about temperatures near the seabed or throughout the water column, which is where sandeels spend most of their life. In reality, it is unlikely that variation in either sandeel growth or phenology will be attributable to a single variable, and a whole suite of biotic factors, including density-dependent effects (Nagoshi \& Sano 1979), competition with other planktivorous fish such as clupeids and life history trade-offs (Roff 2002) are likely to be important, possibly in complex non-linear ways.

An alternative explanation for the changes in lengthat-date distributions documented in this study is that they are the result of changing patterns of mortality. Types of mortality that would be required to obtain the above results include changes in mortality rates of recently hatched larvae, which could mimic changes in mean hatching date, and size-specific changes in mortality of older fish, which could mimic changes in growth rates and the mean length of fish during chickrearing. Many predators are size-selective, and it is plausible that overall predation pressure at various times of the year and on specific size-classes has changed during the study because of changes in the relative abundance of various predators. We are in effect here modelling only the length-at-date of surviving individuals, and if mortality patterns have changed in a particular way over the period, it would be possible to obtain results similar to those observed. Further 
research should aim to explore the potential impact of changes in mortality on the variations in length-at-date distributions of sandeels we have observed, and attempt to attribute these changes in mortality to ecosystem fluctuations experienced by the sandeels. This may require the collection of additional data and/or the development of more complex statistical models.

While the proximate mechanisms responsible for changes in 0-group length appear to have varied over time, the net result has been that our standardised measure for sandeel length at a fixed date has declined significantly. Wanless et al. (2004) estimated that the decline in sandeel length up to 2002 corresponded to a $40 \%$ decline in energy content. Using the same method on the extended time series up to 2006 indicates that the mean energy content of a 0 -group sandeel at the end of June has now declined by about $60 \%$. This estimate assumes a constant length-energy relationship, whereas data from 2004 show that this relationship can vary, and in that year would have greatly overestimated energy content of a fish (Wanless et al. 2005). It is thus possible that at least in some seasons, the decline in energy content has been even more pronounced. These findings have major implications for the many predators of sandeels because energy density, in particular lipid content, shows a non-linear relationship with fish length, and thus the total energy value of a small fish is markedly lower than that of a larger one (Hislop et al. 1991). 0-group sandeels are a major item in the diet of many seabirds in the Firth of Forth, including the 3 most abundant spp: northern gannet Morus bassanus, Atlantic puffin Fratercula arctica and common guillemot Uria aalge (Daunt et al. 2008). The decline in sandeel length means that birds have to catch more items to meet a given energy requirement. Some spp, notably blacklegged kittiwakes Rissa tridactyla, have shown a significant long-term trend towards later breeding (Wanless et al. 2009). This response potentially acts to offset some of the disparity in trophic mismatching since timing of kittiwake breeding has, to some extent, tracked changes in 0-group length. In the late 1990s, blacklegged kittiwakes in this area showed a highly consistent shift in diet over the breeding season, from feeding predominantly on adult to 0-group sandeels, with the change point thought to coincide with metamorphosis of the larval sandeels to 0-group (Lewis et al. 2001). However, results from the present analysis suggest that the earlier hatching, and thus presumably metamorphosis, of sandeels, coupled with the later breeding of kittiwakes, may have resulted in the kittiwake breeding season now coinciding almost entirely with the period when 0-group sandeels are available but are of smaller size. Kittiwake breeding success in recent years has been below the long-term average
(Frederiksen et al. 2008), and these changes in sandeels could have played a part.

Within the North Sea there are several distinct aggregations of Ammodytes marinus (Wright et al. 2000). Significant regional differences in length-at-age and annual growth rates have previously been found, with sandeels in the Firth of Forth aggregation being smaller and having slower growth rates than elsewhere (Wanless et al. 2004, Boulcott et al. 2007). Results presented here indicate that this regional disparity may have become even more marked in recent years. This potentially has major implications for the Firth of Forth aggregation, since body length is the dominant factor determining when North Sea sandeels mature (Boulcott et al. 2007). Moreover, as fecundity also scales to size, smaller length-at-age is likely to be associated with reduced fecundity-at-age (Macer 1966, Gauld \& Hutcheon 1990). This in turn has consequences for the reproductive potential of the Firth of Forth aggregation, tending to make it more vulnerable to collapse through recruitment overfishing and possibly less able to support a level of fishing mortality as high as elsewhere in the North Sea (Boulcott et al. 2007). Thus evidence of a continued and possibly accelerating decline in length-at-age of sandeels in the Firth of Forth is of major relevance to decisions regarding the re-opening of this region to commercial fishing.

In conclusion, by combining existing data sets in a novel way we have demonstrated that the apparently smooth long-term decline in length-at-date in the Firth of Forth sandeel aggregation since the 1970s can be explained by changes in both hatch date and growth rate, and that changes in these basic growth parameters have been complex and nonlinear. These findings implicate underlying changes in key aspects of sandeel life history, most likely related to the wideranging temperature-related shifts in the North Sea food web observed during the same period. In order to improve our understanding of the importance of these various factors in determining sandeel growth and phenology, further experimental and observational studies are needed: The early life history of sandeels, including spawning behaviour, is poorly known, and experimental mesocosm studies would be extremely valuable, while retrospective studies using existing data might help identify large-scale relationships among sandeels, temperature, predators, prey and competitors. Ideally, the 2 approaches should be combined in collaborations between e.g. physiologists, macroecologists and fisheries scientists.

Acknowledgements. Thanks to M. Harris, M. Newell and everyone else who collected fish from puffins on the Isle of May. Thanks to M. Harris, F. Daunt, S. Greenstreet, E. Guirey and 3 anonymous referees for useful comments on an earlier 
version of this manuscript, and to J. Rice, S. Greenstreet, E. Guirey and several anonymous reviewers for constructive comments on the present version. We thank the Natural Environment Research Council and the Joint Nature Conservation Committee for supporting the long-term seabird studies on the Isle of May, and Scottish Natural Heritage for allowing us to work on the Isle of May. N. Halliday (Marine Biological Association of the United Kingdom) extracted and measured additional sandeel larvae. SST data were supplied by the UK Meteorological Office through the British Atmospheric Data Centre. This work was partly funded by the Centre for Ecology and Hydrology Environmental Change Integrating Fund project SPACE (Shifting Phenology: Attributing Change across Ecosystems).

\section{LITERATURE CITED}

Arnott SA, Ruxton GD (2002) Sandeel recruitment in the North Sea: demographic, climatic and trophic effects. Mar Ecol Prog Ser 238:199-210

Beaugrand G (2004) The North Sea regime shift: evidence, causes, mechanisms and consequences. Prog Oceanogr 60:245-262

> Beaugrand G, Reid PC (2003) Long-term changes in phytoplankton, zooplankton and salmon related to climate. Glob Change Biol 9:801-817

- Beaugrand G, Reid PC, Ibañez F, Lindley JA, Edwards M (2002) Reorganization of North Atlantic marine copepod biodiversity and climate. Science 296:1692-1694

Beaugrand G, Brander KM, Lindley JA, Souissi S, Reid PC (2003) Plankton effect on cod recruitment in the North Sea. Nature 426:661-664

Boulcott P, Wright PJ, Gibb FM, Jensen H, Gibb IM (2007) Regional variation in maturation of sandeels in the North Sea. ICES J Mar Sci 64:369-376

> Brunel T, Dickey-Collas M (2010) Effects of temperature and population density on von Bertalanffy growth parameters in Atlantic herring: a macro-ecological analysis. Mar Ecol Prog Ser 405:15-28

> Castonguay M, Plourde S, Robert D, Runge JA, Fortier L (2008) Copepod production drives recruitment in a marine fish. Can J Fish Aquat Sci 65:1528-1531

> Daan N, Bromley PJ, Hislop JRG, Nielsen NA (1990) Ecology of North Sea fish. Neth J Sea Res 26:343-386

> Daunt F, Wanless S, Greenstreet SPR, Jensen H, Hamer KC, Harris MP (2008) The impact of the sandeel fishery closure on seabird food consumption, distribution, and productivity in the northwestern North Sea. Can J Fish Aquat Sci 65:362-381

Dulvy NK, Rogers SI, Jennings S, Stelzenmüller V, Dye SR, Skjoldal HR (2008) Climate change and deepening of the North Sea fish assemblage: a biotic indicator of warming seas. J Appl Ecol 45:1029-1039

- Edwards M, Richardson AJ (2004) Impact of climate change on marine pelagic phenology and trophic mismatch. Nature 430:881-884

Edwards M, Beaugrand G, Reid PC, Rowden AA, Jones MB (2002) Ocean climate anomalies and the ecology of the North Sea. Mar Ecol Prog Ser 239:1-10

Edwards M, Johns DG, Leterme SC, Svendsen E, Richardson AJ (2006) Regional climate change and harmful algal blooms in the northeast Atlantic. Limnol Oceanogr 51: 820-829

Fransz HG, Colebrook JM, Gamble JC, Krause M (1991) The zooplankton of the North Sea. Neth J Sea Res 28:1-52

Frederiksen M, Edwards M, Richardson AJ, Halliday NC,
Wanless S (2006) From plankton to top predators: bottomup control of a marine food web across four trophic levels. J Anim Ecol 75:1259-1268

- Frederiksen M, Jensen H, Daunt F, Mavor RA, Wanless S (2008) Differential effects of a local industrial sand lance fishery on seabird breeding performance. Ecol Appl 18: 701-710

Furness RW (2002) Management implications of interactions between fisheries and sandeel-dependent seabirds and seals in the North Sea. ICES J Mar Sci 59:261-269

> Gauld JA, Hutcheon JR (1990) Spawning and fecundity in the lesser sandeel, Ammodytes marinus Raitt, in the northwestern North Sea. J Fish Biol 36:611-613

> Gelman A, Rubin DB (1992) Inference from iterative simulation using multiple sequences. Stat Sci 7:457-511

> Genner MJ, Halliday NC, Simpson SD, Southward AJ, Hawkins SJ, Sims DW (2010) Temperature-driven phenological changes within a marine larval fish assemblage. J Plankton Res 32:699-708

Hays GC, Richardson AJ, Robinson C (2005) Climate change and marine plankton. Trends Ecol Evol 20:337-344

Hislop JRG, Harris MP, Smith JGM (1991) Variation in the calorific value and total energy content of the lesser sandeel (Ammodytes marinus) and other fish preyed on by seabirds. J Zool (Lond) 224:501-517

Hughes SL (ed) (2004) Scottish ocean climate status report 2002-2003. Fisheries Research Services, Aberdeen

Hunt Jr. GL, Stabeno P, Walters G, Sinclair E, Brodeur RD, Napp JM, Bond NA (2002) Climate change and control of the southeastern Bering Sea pelagic ecosystem. Deep-Sea Res II 49:5821-5853

International Council for the Exploration of the Sea (ICES) (2007) Report of the ICES Advisory Committee on Fishery Management, Advisory Committee on the Marine Environment and Advisory Committee on Ecosystems, Book 6. Copenhagen

Kirby RR, Beaugrand G, Lindley JA (2008) Climate-induced effects on the meroplankton and the benthic-pelagic ecology of the North Sea. Limnol Oceanogr 53:1805-1815

Kirby RR, Beaugrand G, Lindley JA (2009) Synergistic effects of climate and fishing in a marine ecosystem. Ecosystems 12:548-561

> Lewis S, Wanless S, Wright PJ, Harris MP, Bull J, Elston DA (2001) Diet and breeding performance of black-legged kittiwakes Rissa tridactyla at a North Sea colony. Mar Ecol Prog Ser 221:277-284

Macer CT (1966) Sand eels (Ammodytidae) in the south-western North Sea: their biology and fishery. Fishery Investigations Series II, Vol XXIV, no. 6. Ministry of Agriculture, Fisheries and Food, London

Mackenzie BR, Schiedek D (2007) Long-term sea surface temperature baselines: time series, spatial covariation and implications for biological processes. J Mar Syst 68:405-420

> Millar RB, Fryer RJ (1999) Estimating the size-selection curves of towed gears, traps, nets and hooks. Rev Fish Biol Fish 9:89-116

> Monaghan P (1992) Seabirds and sandeels: the conflict between exploitation and conservation in the northern North Sea. Biodivers Conserv 1:98-111

Nagoshi M, Sano M (1979) Population studies of the sand eel, Ammodytes personatus, in Ise Bay. I. Growth and its relation to population density. Jap J Ecol 29:1-10

> Pedersen SA, Lewy P, Wright P (1999) Assessments of the lesser sandeel (Ammodytes marinus) in the North Sea based on revised stock divisions. Fish Res 41:221-241

> Perry AL, Low PJ, Ellis JR, Reynolds JD (2005) Climate change and distribution shifts in marine fishes. Science 
308:1912-1915

Richardson AJ, Schoeman DS (2004) Climate impact on plankton ecosystems in the Northeast Atlantic. Science 305:1609-1612

Rindorf A, Wanless S, Harris MP (2000) Effects of changes in sandeel availability on the reproductive output of seabirds. Mar Ecol Prog Ser 202:241-252

Roff D (2002) Life history evolution. Sinauer Associates, Sunderland, MA

Smith BJ (2007) boa: an R package for MCMC output convergence assessment and posterior inference. J Stat Softw 21:1-37

Sydeman WJ, Bradley RW, Warzybok P, Abraham CL and others (2006) Planktivorous auklet Ptychoramphus aleuticus responses to ocean climate, 2005: Unusual atmospheric blocking? Geophys Res Lett 33:L22S09

van Deurs M, van Hal R, Tomczak MT, Jónasdóttir SH,

Editorial responsibility: Jake Rice,

Ottawa, Ontario, Canada
Dolmer P (2009) Recruitment of lesser sandeel Ammodytes marinus in relation to density dependence and zooplankton composition. Mar Ecol Prog Ser 381:249-258

> Wanless S, Wright PJ, Harris MP, Elston DA (2004) Evidence for decrease in size of lesser sandeels Ammodytes marinus in a North Sea aggregation over a 30 -yr period. Mar Ecol Prog Ser 279:237-246

Wanless S, Harris MP, Redman P, Speakman J (2005) Low energy values of fish as a probable cause of a major seabird breeding failure in the North Sea. Mar Ecol Prog Ser 294:1-8

Wanless S, Frederiksen M, Walton J, Harris MP (2009) Longterm changes in breeding phenology at two seabird colonies in the western North Sea. Ibis 151:274-285

Wright PJ, Jensen H, Tuck I (2000) The influence of sediment type on the distribution of the lesser sandeel, Ammodytes marinus. J Sea Res 44:243-256

Submitted: November 26, 2009; Accepted: April 21, 2011

Proofs received from author(s): June 6, 2011 